readers might assume can be "taken as read." Hence I was astonished to find that only two of its seven conclusions (and these two were statements of the obvious) could withstand rigorous scrutiny.

I would thus challenge the assertion by Mueller et al that breast cancer is most rapidly lethal in the elderly, and suggest that the authors have erred in completely ignoring the possibility that the disease is diagnosed relatively late in older women. The recent paper by Dr W H Redding and his colleagues on age and prognosis in breast cancer (2 June, p 1465) comes to the same conclusion.

\section{David Belasco}

\section{Swaffham, Norfolk PE37 8DD}

1 Mueller, C B, Ames, F, and Anderson, G D, Surgery, $1978,83,123$

** It is an uncomfortable though hardly an unscientific fact that the majority of women who present with carcinoma of the breast will die of their disease. For a start, something like $30-40 \%$ of all women who present with breast cancer have either locally advanced or widely disseminated disease on presentation. ${ }^{1}$ This group as a whole have little chance of living five years after diagnosis. ${ }^{1}$ The remainder presenting with "operable or potentially curable" breast cancer can be expected to demonstrate an approximate $50 \%$ 10-year survival, irrespective of primary modalities of therapy." Ten years' survival, however, does not in itself guarantee cure, and two series with long-term follow-up have clearly demonstrated that the excess risk of dying applies up to 20 years or more after primary therapy, providing an estimated $30 \%$ cure rate. ${ }^{34}$ The data have nothing to do with Mueller's article and should be widely known to all clinicians involved in the treatment of breast cancer. If uncomfortable facts cannot be published in a medical journal, then we would indeed be burying our heads in the sand.

It is true that in Mueller's article, and also in the short paper by Dr Redding and his colleagues, there was a small disproportionate increase in the incidence of stage III and unstaged breast cancers among the elderly. However, Mueller and his colleagues took the trouble to exclude the unstaged cases from the analysis and to correct according to stage at diagnosis in making their comparisons between the age groups. Thus, to quote from their conclusion, "Age as well as stage at diagnosis are significant determinants of the length of survival and cause of death." But "late" breast cancer may in part reflect its aggressive nature and not simply the delay in presentation on the patients' part. ${ }^{5}-\mathrm{ED}, B M \mathcal{F}$.

${ }^{1}$ Cutler, S J, Seminars in Oncology, 1974, 1, 91.

2 Fisher, B, Cancer, 1973, 31, 1271

3 Adair, F, et al, Cancer, 1974, 33, 1145

Arinkley, D, and Haybittle, J L, Lancet, 1975, 2, 95

5 Devitt, J E, in Risk Factors in Breast Cancer, ed B A Stoll, p 110. London, Heinemann Medical, 1976.

\section{Costs of unnecessary tests}

SIR,-Dr Gerald Sandler's timely and important paper (7 July, p 21) on the cost of unnecessary tests omitted one relevant fact. The unnecessary investigations performed by the doctor in outpatients have already probably been unnecessarily performed by the GP, and the results given in the referral letter. Discussions with colleagues from around the country suggest that it is very rare for such prereferral tests not to be repeated in the clinic. The potential saving from dropping at least one tier of this over-investigation could be huge.

\section{Haslam}

Huntingdon, Cambs

\section{Seat-belt legislation}

SIR,-Dr Gordon Avery (9 June, p 1561) assumes that infringement of a law enforcing the use of seat belts would be easy to detect. During a recent holiday in Spain, however, where the wearing of seat belts outside urban areas is compulsory, I discovered that those who object to wearing seat belts have a simple method of getting round the law. They pass the seat belt across their bodies but do not fasten the buckle. This makes detection practically impossible; though in the event of an accident the pattern of injury might well reveal the true situation.

This way round the law, far from making things more difficult for the police, removes two of the main objections to the introduction of legislation. In the first place, it means that any motorist with a conscientious objection to the use of a seat belt could continue to exercise his conscience without fear of detection. Also, since detection in these circumstances is practically impossible, the police would have no major problem of enforcement.

The most important deterrent to disobeying the law would come, however, not from the police, but from the insurance companies. If the wearing of seat belts were made compulsory then, in the event of an accident resulting in injury that would have been prevented by the wearing of a seat belt, the insurance companies could impose much stiffer penalties with the backing of the law. I am sure that widespread publicity regarding reduction of the damages to those who do not wear seat belts would do far more to encourage conformity to the law than any police measures.

We should therefore cease concerning ourselves with the imaginary problem of the $10 \%$ who will refuse to wear seat belts and concentrate on the known benefits to the $90 \%$ who will obey the law.

A W FOWLER

Bridgend General Hospital, Mid Glamorgan

\section{Diazepam and traffic accidents}

SIR,-In the epidemiological survey by Dr D C G Skegg and others (7 April, p 917) it was clearly shown that drivers who receive minor tranquillisers are significantly over-represented among accident victims. The authors also point out that studies of this type fail to distinguish between the effects of the drug and of the condition being treated.

People are prescribed tranquillisers because they are anxious, aggressive, or depressed, and it is recognised that these patients are more likely to be involved in accidents. ${ }^{1}$ Notwithstanding numerous claims, the detrimental effect of diazepam on driving ability has never been established. There is considerable evidence that critical flicker fusion frequency is significantly reduced by small doses of diazepam. No case has been made, however, that reduced critical flicker fusion frequency is in any way deleterious to driving ability. A statistically significant increase and reduction in reaction time (both have been reported) does not necessarily harm driving performance. Some psychomotor tests have shown that benzodiazepines at times improve and at other times impair performance: no relationship between these skills and driving ability has been established. The presence of diazepam and its metabolites in the blood of drivers involved in car accidents varies from under $2 \%$ in a recent New Zealand study ${ }^{2}$ to nearly $20 \%$ in an older Norwegian survey. ${ }^{3}$

As a general rule, it is preferable that anxious, aggressive, and depressed patients do not drive: with diazepam medication ${ }^{*}$ driving safety could deteriorate, remain unchanged, or improve.

A LANDAUER

University of Western Australia,
Nedlands, Western Australia 6009

${ }^{1}$ Milner, G, Drugs and Driving. Basle, Karger, 1972. Missen, A W, et al, New Zealand Medical fournal, $1978,87,275$

Bø, O, et al, in Alcohol, Drugs and Traffic Safety, ed $S$ Israelstam and S Lambert. Toronto, Addiction Research Foundation, 1975.

\section{Whooping cough after stopping pertussis} immunisation

SIR,-For too long the whooping cough debate has been fuelled by data whose interpretation leaves too much to speculation. Dr Robert $\mathrm{K}$ Ditchburn's (16 June, p 1601) study is no exception. The attack rate in children aged $3 \frac{1}{2}$ to 15 years is $45 \%$. It would be valuable to see the age incidence of these cases and it would shed light either on the efficacy of the vaccine with age or on an unusual pattern of attack in older children.

The Keyworth study ${ }^{1}$ showed reducing protection of the vaccine up to 5 years, but this was evident only because there was an adequate control group. Surely it is unreasonable to compare $3 \frac{1}{2}$ to 15 year olds with under $3 \frac{1}{2}$ year olds.

The Keyworth study showed $84.4 \%$ protection in 1 to 4 year olds. If I recalculate my data using Dr Ditchburn's system and compare unimmunised children under $3 \frac{1}{2}$ with immunised children aged $3 \frac{1}{2}$ to 7 years, the apparent protection falls to $50 \%$ - a very important difference.

Douglas Jenkinson Keyworth Health Centre,
Keyworth, Notts NG12 5JU

${ }^{1}$ Jenkinson, D, British Medical fournal, 1978, 2, 577.

** We sent a copy of this letter to the author, whose reply is printed below.-ED, $B M \mathcal{H}$.

SIR,-I thank Dr Douglas Jenkinson for his comments on my paper. In the outbreak I describe, whooping cough occurred in six of seven immunised children aged $3 \frac{1}{2}$ to 5 years; in 18 of 42 aged 6 to 10 years; and in 22 of 44 children aged 11 to 15 years. Thus any reduction of vaccine efficiency with age, if it occurred, must have been before the age of $3 \frac{1}{2}$ years.

I do not accept that the pattern of attack in older children is necessarily unusual, though in remote Shetland it could well be so. Until there are more studies in which the unaffected children are positively identified, the "usual" attack rate in older children will not be known.

I accept the limitations of comparing children in different age groups. Of course, if it is true that young children are more susceptible to whooping cough, my study comparing young immunised children with 